\title{
Primary angioplasty in myocardial infarction
}

\section{An introductory overview}

Outcome after myocardial infarction can be improved by prompt reperfusion of the infarct-related coronary artery by thrombolysis or by primary angioplasty. Despite the uncertain role for coronary angioplasty as an early intervention after successful thrombolytic therapy, it seems that primary angioplasty can open acutely occluded arteries as effectively as does thrombolysis, making it a rational first intervention for acute infarction in patients in whom thrombolytic therapy is relatively contraindicated. Indeed, several recent studies have suggested that primary angioplasty during the early hours of myocardial infarction may be even more likely than thrombolysis to establish stable reperfusion. These observations raise important questions that are central to the future of coronary care. Problems for discussion and resolution extend beyond the scientific conclusions of ongoing studies to the regional logistic, political, and ethical implications of these findings.

Emerging data strongly support a role for acute angioplasty where it is available and accessible, but the extent and limitations of this role require further clarification. Patient populations with infarction are generally more heterogeneous than those included in selected clinical trials. Are we now at a point where acute angioplasty represents optimal care for some patients with evolving myocardial infarction? Precisely which patients are these, and what additional studies are needed to identify them? What are the end points that govern the overall value of these methods? Is angioplasty directly competitive with thrombolysis as a primary intervention, or are these techniques likely to be complementary? And if they are complementary, which subgroups of patients might be most effectively treated with each method?

Thrombolysis can be undertaken in centres that provide relatively little technical and laboratory support. Angioplasty requires not only an experienced operator but also continuous staffing of an accessible catheterisation facility. However favourable primary angioplasty may be when performed by enthusiasts during focused trials in large clinical centres, limitations and problems with the method undoubtedly will emerge with growing experience in suboptimal settings, particularly during awkward hours. What will be the comparative value of these methods when they are applied under average conditions, with average technical support? What will be the relative consequences of these methods for the subsequent course and duration of hospital stay, including further use of laboratory resources? Are the ultimate logistics of primary angioplasty more closely defined by the community hospital than by the university centre?

Economic, logistic, and ethical issues arise in parallel with scientific debate. If primary angioplasty is shown to confer important benefit on some patients with acute myocardial infarction, what reasons might limit its general availability? How much would it cost to make these procedures widely accessible? What would be the consequences of widespread adoption of these evolving coronary care strategies for physician training in cardiology, distribution of consultants, technical staffing and support, and laboratory use? Are these medical, political, or ethical problems? Who should decide whether new approaches are appropriate, who should decide when they should be implemented, and who should decide if they are worth the cost?

PAUL KLIGFIELD

Division of Cardiology, Department of Medicine, The New York Hospital-Cornell Medical Center, 525 East 68th Street, New York, New York 10021,

$U S A$

\section{Primary angioplasty is the most effective treatment for an acute myocardial infarction}

\section{$A$ view from the Netherlands}

Over the past decades, great efforts have been made to assess the optimal approach to patients with acute myocardial infarction. Although the use of aspirin, ${ }^{1}$ $\beta$ adrenergic blockers, ${ }^{2}$ and angiotensin converting enzyme inhibitors ${ }^{3}$ has significantly reduced mortality in these patients, attention has focused on the restoration of normal blood flow in the infarct-related coronary artery. Coronary artery bypass grafting was the only accepted revascularisation therapy in the $1970 \mathrm{~s}$. Although data from small studies suggested that the results of early reperfusion by means of bypass grafting were promising, ${ }^{45}$ this approach was never tested in large scale studies. In the 1980s intravenous thrombolytic therapy. became widely used, with an estimated average reduction of early mortality of $20-30 \% .^{1367}$ Different thrombolytic regimens do result in small differences in clinical outcome ${ }^{8}$ but all are associated with only modest reperfusion rates. Normal flow (TIMI 3) in the infarct-related artery 90 minutes after the start of thrombolytic therapy was found in $29-54 \%$, and $5-7$ days later in $51-58 \% .{ }^{78}$ After several major trials showed that angioplasty performed immediately after thrombolytic therapy conferred no additional benefit ${ }^{910}$ interest in the role of angioplasty as a treatment for acute infarction dwindled. Thrombolytic therapy followed by "watchful waiting" became an almost universally accepted approach. ${ }^{11}$ The simultaneous publication of three trials in which this approach was compared with primary coronary angioplasty (angioplasty without prior or concomitant administration of thrombolytic drugs) has rekindled the debate on the role of angioplasty. ${ }^{12-14}$

PATENCY OF THE INFARCT-RELATED ARTERY

Primary angioplasty performed by experienced operators restores normal (TIMI 3 flow) blood flow in more than $90 \%$ of patients. ${ }^{12-15}$ Reocclusion rates after angioplasty are low. ${ }^{13}$ This compares favourably with the $50-70 \%$ of patients in whom normal flow is achieved after thrombolytic therapy. ${ }^{813}$ 


\section{MYOCARDIAL SALVAGE}

Myocardial salvage can be assessed by determining enzymatic infarct size and by measuring regional or global left ventricular function. Enzymatic infarct size calculated from serial measurements of lactate dehydrogenase was smaller in patients randomised to angioplasty than in those randomised to streptokinase, and this difference was most pronounced in patients admitted to the hospital within 2 hours after the onset of symptoms. ${ }^{15}$ In the same study global and regional left ventricular function were better preserved by angioplasty, again with a strong relation between time from symptom onset to admission and myocardial salvage. The longer delay before treatment probably explains why the Mayo clinic trial did not show a difference in myocardial salvage. ${ }^{14}$ Data on enzymatic infarct size and left ventricular function strongly favour angioplasty, especially in patients with anterior wall infarctions and patients coming into hospital soon after the onset of symptoms. ${ }^{15}$

\section{MORTALITY AND CLINICAL OUTCOME}

Although data from two of the three trials suggested that mortality was lower after angioplasty than after thrombolytic therapy, ${ }^{12}{ }^{16}$ none of these studies was large enough to answer this crucial question definitely. A pooled analysis of these three trials, however, makes it clear that clinical outcome is better after primary angioplasty than after thrombolytic therapy. Mortality in the thrombolytic groups was $6.4 \%$ (comparable with the GUSTO data), whereas the mortality in the angioplasty groups was $2.5 \%$ $(P=0.008)$. This represents a risk reduction ratio of 2.5 ( $95 \%$ confidence interval (CI) $1 \cdot 2$ to $5 \cdot 6$ ). Similarly, the risk of reinfarction was reduced from $7 \cdot 9 \%$ to $2.0 \%$ $(\mathrm{P}<0.001, \mathrm{CI} 1.8$ to 8.4$)$ in angioplasty patients. Finally, angioplasty resulted in a 9.7 risk reduction ratio $(2.5 \%$ compared with $0.3 \% ; \mathrm{P}=0.007, \mathrm{CI} 1.3$ to 75.6 ) in the incidence of stroke. Freedom from any of these events was seen in $95 \%$ of angioplasty patients compared with $85 \%$ of patients randomised to thrombolytic therapy. Patients with anterior wall infarctions and/or signs of left ventricular dysfunction benefited most from angioplasty. ${ }^{16}$

\section{"A pooled analysis of trials makes it clear that clinical outcome is better after primary angioplasty than after thrombolytic therapy"}

ARE THESE EFFECTS SUSTAINED?

The frequency of restenosis after primary angioplasty has not been studied extensively. The available quantitative angiographic data suggest a restenosis frequency around $25 \%$, but reocclusions are rare. ${ }^{13}$ Follow up data show a low rate of post-infarction angina, very few reinfarctions, and rates of intervention and hospital re-admission that are lower than after thrombolytic therapy. ${ }^{17}$

IS PRIMARY ANGIOPLASTY GOING TO INFLATE THE ALREADY STAGGERING COSTS OF MEDICAL CARE? In the "Zwolle" trial the total medical costs of all patients, including hospital costs, professional charges, procedures and medication, were calculated. ${ }^{13}{ }^{15-17}$ After 1 year of follow up the costs were DFl 26.355 per patient in the angioplasty group and DFl $25.027(P=0.12)$ in the streptokinase group. The efficacy of both treatments can be estimated by calculating the mean cost per event free survivor (which was DFl 29.280 for an angioplasty patient and DFl 34.941 for a streptokinase patient).

HOW SHOULD THIS INFORMATION BE APPLIED?

Although in some hospitals it would be feasible for all patients with a myocardial infarction to have an angioplasty, most patients with an acute myocardial infarction would need to be transported to a centre with angioplasty facilities. This would be difficult to achieve. Therefore it seems more appropriate to treat "low risk" patients with thrombolytics and focus the attention of the interventional cardiologists on "high risk" patients, such as patients with large anterior wall infarcts or with signs of haemodynamic instability. We have performed a pilot study showing the feasibility of this approach. The two most important issues are the definition of "high risk" and the logistics of safe and rapid transportation of these critically ill patients from the emergency room of a general hospital to a catheterisation laboratory with an experienced team of interventional cardiologists. A multicentre trial under the auspices of the Interuniversity Cardiology Institute of the Netherlands started in 1995 to test the safety, feasibility, and efficacy of treating low risk and high risk patients differently.

FELIX ZIJLSTRA Department of Cardiology, The Weezenlanden Hospital, 8011 fW Zwolle, The Netherlands

1 ISIS-2 Collaborative Group. Randomised trial of intravenous streptokinase, oral aspirin, both, or neither among 17,187 cases of suspected acute myocardial infarction. Lancet 1988;ii:349-60.

2 Yusuf S, Peto R, Lewis J, Collèris R, Sleight P. Beta blockade during and after myocardial infarction: an overview of the randomized trials. Pro Cardiovasc Dis 1985;27:335-71.

3 Simoons ML. Myocardial Infarction: ACE-inhibitors for all? For ever? Lancet 1994;344:279-81.

4 Loop FD, Cheanvechai C, Sheldon WC, Taylor PC, Effler DB. Early myocardial revascularization during acute myocardial infarction. Chest 1974;66:478-82.

5 DeWood MA, Spores J, Notske R, et al. Medical and surgical management of acute myocardial infarction. Am $\mathcal{F}$ Cardiol 1979;44:1356-64

6 Gruppo Italiano per lo Studio della Streptochinasi nell'Infarto Miocardico (GISSI). Effectiveness of intravenous thrombolytic treatment in acute (GISSI). Effectiveness of intravenous thromb

7 Granger CB, Califf RM, Topol EJ. Thrombolytic therapy for acute myocardial infarction. A review. Drugs 1992;44:293-325.

8 The GUSTO Angiographic Investigators. The effects of tissue plasminogen activator, streptokinase, or both on coronary-artery patency, ventricular function, and survival, after acute myocardial infarction. $N$ Engl $f$ Med 1993;329:1615-22.

9 Simoons ML, Arnold AER, Betriu A, et al. Thrombolysis with tissue plasminogen activator in acute myocardial infarction: no additional benefit from immediate percutaneous coronary angioplasty. Lancet 1988;i: 197-203.

10 TIMI Research Group. Immediate vs delayed catheterization and angioplasty following thrombolytic therapy for acute myocardial infarction. TIMI 2 A results. $\Im A M A 1988 ; 260: 2849-58$.

11 Meier B. Balloon angioplasty for acute myocardial infarction. Was it buried alive? Circulation 1990;82:2243-5.

12 Grines CL, Browne KF, Marco J, et al for the Primary Angioplasty in Myocardial Infarction Study group. A comparison of immediate angioplasty with thrombolytic therapy for acute myocardial infarction. $N$ Engl plasty with thrombolytic

13 Zijlstra F, de Boer MJ, Hoorntie JCA, Reiffers S, Reiber JHC Suryapranata $\mathrm{H}$. A comparison of immediate coronary angioplasty with intravenous strep

14 Gibbons RJ, Holmes DR, Reeder GS, Bayley KR, Hopfenspirger MR Gersh BJ. Immediate angioplasty compared with the administration of a thrombolytic agent followed by conservative treatment for myocardia infarction. N Engl F Med 1993;328:685-91.

15 de Boer MJ, Suryapranata H, Hoorntje JCA, et al. Limitation of infarct size and preservation of left ventricular function after primary coronary angioplasty compared with intravenous streptokinase in acute myocardial infarction. Circulation 1994;90:753-61.

16 de Boer MJ, Hoorntje JCA, Ottervanger JP, Reiffers S, Suryapranata H, Zijlstra F. Immediate coronary angioplasty versus intravenous streptokinase in acute myocardial infarction: left ventricular ejection fraction, hospital mortality and reinfarction. F Am Coll Cardiol 1994;23:1004-8.

17 Zijlstra F, de Boer MJ, Ottervanger JP, Liem AL, Hoorntje JCA Suryapranata $\mathrm{H}$. Primary coronary angioplasty versus intravenous streptokinase in acute myocardial infarction: differences in outcome during a mean follow-up of 18 months. Coronary Artery Disease 1994;5:707-12. 